\title{
Follicular Unit Transplantation Versus Scalp Expansion in Management of Secondary Cicatricial Alopecia
}

\author{
AMR I. ADS, M.Sc.*; MAHMOUD ABDEL-NABI SAEED, M.D.**; \\ AHMED ABO-HASHEM AZAB MOOSA, M.D.** and MOHAMMED HASSAN ABDELAAL, M.D.**
}

The Department of Plastic Surgery Resident*, Al-Shorouq Police Hospital, Cairo, Egypt and

Plastic \& Reconstructive Surgery Department**, Faculty of Medicine, Zagazig University, Egypt

\begin{abstract}
Background: The bad impact of cicatricial alopecia among population leads to increase the desire of correcting that type of hair loss. There are many methods of hair restoration, but the efficacy of each, its indications and the possible hazards hasn't yet been clearly identified.

Objective: To evaluate the use of two different techniques for hair restoration in patients with secondary cicatricial alopecia. Either using follicular unit extraction (FUE) or scalp expanders (SE) to correct the deformity depending upon many factors (Inclusion \& Exclusion criteria). Indications, operative time, Aesthetic outcome and complications are to be discussed.

Patients and Methods: This study included 30 patients who were grouped into two populations. The first one (Group A) those who underwent FUE included 13 cases while the second group was SE (Group B) included 17. All of them were suffering from secondary cicatricial alopecia and they were grouped according to the surface area of the alopecia.

Results: The mean value of the surface area of alopecia was significantly larger in the SE group than FUE group with a $p$-value $<0.001$. Post-operative recovery was nearly similar apart from being faster gain in group B and better hair density.

Conclusion: In management of secondary cicatricial alopecia, many factors affect surgical planning. Both FUE and SE are very useful tools in managing those patients when properly selected and tailored to the patient.
\end{abstract}

Key Words: Follicular unit - Transplantation - Scalp expansion.

\section{INTRODUCTION}

Cicatricial alopecia (CA) refers to scarring that ends up with loss of hair due to a set of various diseases which devastate the hair follicle. They turn the hair follicle into a scar tissue with permanent hair loss [1].

CA is further subdivided into primary and secondary. In primary CA the stable portion of the hair follicle (stem cells of the bulge area and the infundibulum) is the target of the destructive in- flammatory process. This may occur in the course of an auto-immune process (e.g. Lichen planopilaris and Discoid lupus erythematosus) or infectious process (e.g. Folliculitis decalvans) [2].

Secondary CA result from damage of the hair follicle as a part of non-follicle directed process or injury. This may occur with burns, trauma, radiation or skin infections like tinea capitis [3].

Surgical correction of CA is highly valuable. Many surgical approaches are used. Hair transplantation, surgical excision of hairless areas and/or flap procedures with the preliminary use of skin expansion techniques are all used for this purpose [1].

Surgical excision of scarred areas over the scalp is used to treat small areas of secondary CA. To treat larger areas (scars wider than $5 \mathrm{~cm}$ ), tissue expander may be inserted under the normal scalp adjacent to the area of alopecia (Scalp Expansion, $\mathrm{SE})$. It is then progressively filled with normal saline over a period of 8-12 weeks. The expanded hair-bearing scalp is then advanced or rotated to fill the surgical defects created after excision of the scarred alopecic area [4].

Hair transplantation is the harvesting hair follicles from a suitable hairy area (donor site-usually occipital or occipito-parietal). This harvesting may be done by either strip excision or follicular unit extraction (FUE). After that the prepared follicular units are grafted and implanted into the area of alopecia (recipient site) [5].

In this work we present our experience and results of managing patients with secondary CA using either FUE technique for hair transplantation or SE for correcting such a deformity. 


\section{PATIENTS AND METHODS}

This work was done in Department of Plastic and Reconstructive Surgery, Faculty of Medicine, Zagazig University within the period from Sep. 2017 to Sep. 2018. It included 30 patients, all of them were suffering from secondary CA. Patients demographic data are all illustrated in Table (1). Group A involved 13 patients, were managed using FUE technique for hair restoration. While group B included 17 patients, SE group. Table (1) reveals absence of any significant difference between both groups with respect to age, sex, residence and occupation.

\section{Group A (FUE Group):}

Patients of this group were 13, all of them suffered from 2ry CA. Those patients were chosen according to certain inclusion criteria:

1- Age >15 years: To be able to understand the procedure and its related postoperative instructions (Table 1).

2- Surface area of the scarred area is small with a mean of $19 \mathrm{~cm}^{2}$ (Table 2).

FUE was done as day surgery. Informative signed consent was obtained from the patient or his medico-legal guardian before proceeding. Patients were instructed to shave their hair to the length of $1 \mathrm{~mm}$. During harvesting of follicular units, the patient was seated on a comfortable chair with the head supported and leaning forward (donor site was occipital and/or occipito-parietal). Preoperative medications were given to all cases in the form of broad spectrum antibiotic (Sulbctam and Amoxicillin 1.5gm vial IV). Occipital and post auricular nerve blockage was obtained using local infiltration anesthesia, (Fig. 1).

We used the powered SAFE System Fig. (2a), developed by Dr. Jim Harris, which uses blunt dissection punch to isolate the follicular units from the surrounding tissue Fig. (2b) [6].

Fig. (3) (from a to e) shows the operative steps of FUE procedure. All patients were given postoperative medications (pre-operative ones + Diclofenac sodium $75 \mathrm{mg}$ tab as moderate pain killer). Some patients were advised to put ice bags over the eyes and forehead for the $1^{\text {st }} 48$ hours to combat edema. The first Post-operative dressing was done 3 days later, the patient came to the outpatient clinic and the dressing was removed very slowly under running normal saline. Patients started washing the scalp by anti-dandruff shampoo after another 3 days.

\section{Group B (SE Group):}

Patients of this group were 17 , all of them suffered from 2ry CA. Those patients were chosen according to certain inclusion criteria:

1- Age >5 years: As most studies proved that children above this age can tolerate expanders very well [7].

2- Surface area of the scarred area is large with a mean of $142 \mathrm{~cm}^{2}$ (Table 2).

We used rectangular expanders with semi hard base and remote filling port. Their size varied from $250 \mathrm{cc}$ to 400c. Shaving of the area of operation was done in the day of operation. The patient was anaesthetized generally with endo-tracheal intubation in supine position with the head elevated. Prophylactic Broad spectrum antibiotic (Sulbctam and Amoxicillin $1.5 \mathrm{gm}$ vial IV) was administrated intravenously at the start of the operation. Subgaleal injection of saline + adrenaline $(1: 500,000)$ to reduce blood loss. A small incision $2 \mathrm{~mm}$ from margin of the scar was made to insert the expander.

The pocket for tissue expander was dissected $2 \mathrm{~cm}$ larger than the dimensions of the expander in the sub-galeal plane of the scalp (facilitated by the use of a urethral dilator). The pocket is copiously irrigated with an isotonic saline solution, prior to the insertion of the expander, the expander was sited $2 \mathrm{~mm}$ from the edge of the incision to avoid scar expansion and puncture during wound closure. Remote valve was placed at a reasonable distance from the expander on a bony prominence. Complete meticulous hemostasis, insertion of a suction drain and the wound was closed in two-layers with subcutaneous $3 / 0$ or $4 / 0$ vicryl sutures and $2 / 0$ or $3 / 0$ polypropylene sutures for skin closure.

Expansion was started on table once the wound was closed by $10-20 \%$ of the volume of the expander using normal saline and a 23-gauge butterfly needle. However, if blanching or skin tension is noted, fluid was withdrawn. Suction drain was removed 5 days post-operative and stitches were removed on day 14 post-operative. Expansion was continued after one week later (three weeks PO) being sure that the wound healed nicely without complications.

After six months of follow-up, a five point questionnaire was made for all cases to measure their opinion in:

1- Hair density at the treated area.

2- Proper hiding of the scars post operatively.

3- Hair direction related to its new position.

4- Their general satisfaction. 
5- How much they advise other patients to go for the same surgery.

Their answers were graded as: Excellent (86$100 \%)$, very good $(65-85 \%)$, good $(50-64 \%)$, bad $(30-49 \%)$ and poor $(<30 \%)$.

\section{RESULTS}

Post-burn scarring was found to be the leading cause of 2ry cicatricial alopecia in both groups of patients included in this work, Table (2). It represented $61.5 \%$ in group A and $52.9 \%$ in group B.

Table (3) reveals a highly statistically significant difference between both groups regarding the mean surface area of alopecia and time elapsed since injury ( $p$-values are 0.0006 and 0.001 respectively), while the difference was statistically insignificant with respect to operative time.

Table (4) shows the number of estimated hair follicles needed \& the number of sessions in Group A. Two sessions were done in two patients only (Add-on session). It also shows the estimated size of expander, the maximum size of expansion reached and the need for more than one stage of expansion in Group B. There were two cases that needed two stages of expansion (two surgeries for each stage).

Table (5) represents the complications recorded in both groups. In Group A, while there was no complications in the donor site (white scar, pseudosyphilitic appearance or necrosis) or anesthesiarelated complications, there was some complications in the recipient, in the form of partial loss of transplants in 4 cases $(30.77 \%)$, transplanted hair thinning in one $(7.69 \%)$ and un-satisfaction in two $(15.38 \%)$. While in Group B hematoma was recorded in two cases (11.76) and seroma, expander exposure and expander loss in one case each (5.88\%). Unsatisfied patient/parent and anesthesiarelated complications, both, were zero.

Table (6) shows the statistical analysis of patient questionnaire about the results and patient satisfaction. In general, no patient/parent assigns excellent results in both Groups $(0 \%)$. Speaking of general satisfaction, very good results were reported in 7 cases (53.8\%) in Group (A) \& 12 cases (70.6\%) in Group (B). In concern to hair density: no patient assigns excellent results in both Groups (0\%) also, very good results reported in 7 cases $(53.8 \%)$ in Group (A) \& 10 cases (58.8\%) in Group (B) while good results were found in 3 cases $(23.1 \%)$ in Group (A) \& 4 cases in Group (B) (23.5\%). Hair direction was reported to be very good and good in Group A in 8 and 3 cases $(61.5 \& 23.1 \%)$ respectively and in Group B in 11 and 4 cases (64.7 $\& 23.5 \%$ ) respectively also.

Hidden scars were very good in 7 cases $(53.8 \%)$ in Group (A) \& 12 cases of Group (B) (70.6\%) and good results were found in 4 cases $(30.8 \%)$ in Group (A) \& 5 cases of Group (B) (29.4\%). Finally, advice for other patient to do this surgery from current cases: Very good reported in 9 cases $(69.2 \%)$ in Group (A) \& 13 cases (76.5\%) in Group (B), Table (6), (Figs. 5,6).

Table (1): Demographic data of both groups.

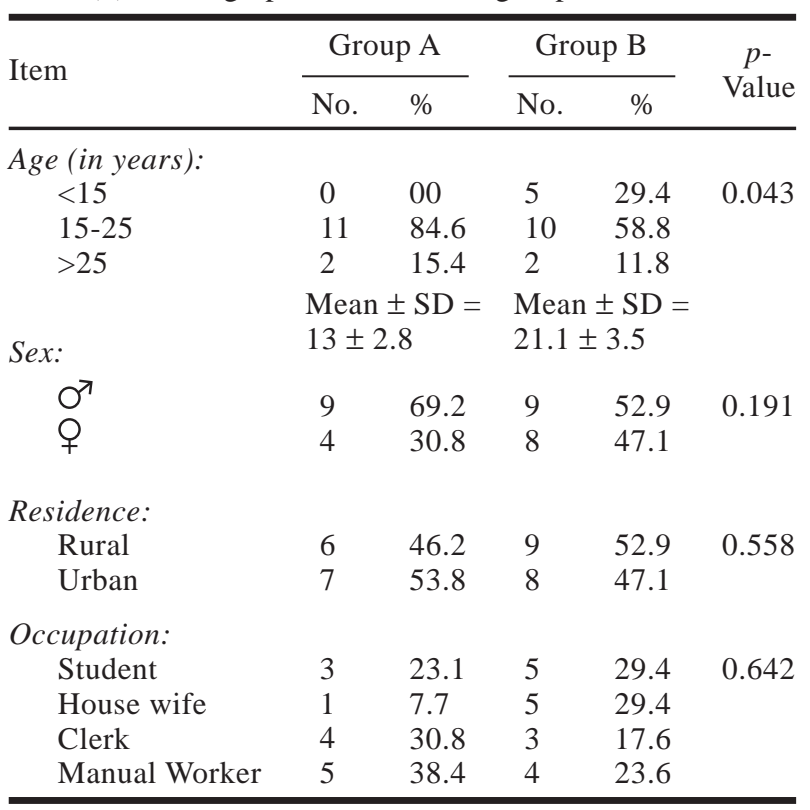

Table (2): Causes of Alopecia in both groups.

\begin{tabular}{lccccc}
\hline \multirow{2}{*}{ Item } & \multicolumn{2}{c}{ Group A } & & \multicolumn{2}{c}{ Group B } \\
\cline { 2 - 3 } \cline { 6 - 6 } \cline { 5 - 6 } & No. & $\%$ & & No. & $\%$ \\
\hline Post-burn & 8 & 61.5 & & 9 & 52.90 \\
Post-trauma & 3 & 23.1 & & 4 & 23.55 \\
Post-tumor Excision & 1 & 7.7 & & 4 & 23.55 \\
Post-Expansion & 1 & 7.7 & & - & - \\
\hline
\end{tabular}

Table (3): Comparison of mean surface area of alopecia, mean time since injury and mean operative time in both groups.

\begin{tabular}{lcccc}
\hline Item & Group A & Group B & $\begin{array}{c}t- \\
\text { test }\end{array}$ & $\begin{array}{c}p- \\
\text { value }\end{array}$ \\
\hline $\begin{array}{l}\text { Mean surface } \\
\text { area of alopecia } \\
\left(\mathrm{cm}^{2}\right)\end{array}$ & $22.91 \pm 15.1$ & $133.62 \pm 66.15$ & 7.423 & 0.0006 \\
$\begin{array}{l}\text { Mean time since } \\
\text { injury (yrs) }\end{array}$ & $12.08 \pm 6.26$ & $4.66 \pm 2.42$ & 3.828 & 0.001 \\
$\begin{array}{l}\text { Mean operative } \\
\text { time (hrs) }\end{array}$ & $3.22 \pm 1.42$ & $4.25 \pm 1.44$ & 1.95 & 0.066 \\
\hline
\end{tabular}


Table (4): Comparison between both groups regarding to intraoperative information.

\begin{tabular}{lll}
\hline Group A: & & \\
No of Estimated Hair Follicles & Range & $150-1200$ \\
& Mean & 441.45 \\
& SD & 308 \\
No of Sessions & One & $11 \mathrm{pt}$ \\
& Two & $2 \mathrm{pt}$ \\
Group B: & & \\
Estimated Expander Size & Range & $250-400 \mathrm{cc}$ \\
& Mean & $312.5 \mathrm{cc}$ \\
& SD & $60 \mathrm{cc}$ \\
Maximum Size Reached & Range & $400-1100 \mathrm{cc}$ \\
& Mean & $725 \mathrm{cc}$ \\
& SD & $208 \mathrm{cc}$ \\
No of Sessions & Two & $15 \mathrm{pt}$ \\
& Four & $2 \mathrm{pt}$ \\
\hline
\end{tabular}

Table (5): Complications in both groups of the study.

\begin{tabular}{llll}
\hline Group & Complication & No. & $\%$ \\
\hline Group A & Partial Transplant Loss & 4 & 30.77 \\
& Transplant Thinning & 1 & 7.69 \\
& Unsatisfied Patient & 2 & 15.38 \\
& Donor-site Morbidity & 0 & 0 \\
& Anesthesia-Related & 0 & 0 \\
Group B & Hematoma & 2 & 11.76 \\
& Seroma & 1 & 5.88 \\
& Expander Exposure & 1 & 5.88 \\
& Expander Loss & 1 & 5.88 \\
& Unsatisfied Patient/Parent & 0 & 0 \\
\hline
\end{tabular}

Table (6): Patient satisfaction for both groups.

\begin{tabular}{|c|c|c|c|c|c|c|c|c|c|c|}
\hline \multirow{2}{*}{ Item } & \multicolumn{2}{|c|}{$\begin{array}{c}\text { Excellent } \\
86-100\end{array}$} & \multicolumn{2}{|c|}{$\begin{array}{l}\text { Very Good } \\
\quad 65-85\end{array}$} & \multicolumn{2}{|c|}{$\begin{array}{l}\text { Good } \\
50-64\end{array}$} & \multicolumn{2}{|c|}{$\begin{array}{c}\text { Bad } \\
30-49\end{array}$} & \multicolumn{2}{|c|}{$\begin{array}{c}\text { Poor } \\
<30\end{array}$} \\
\hline & A & B & A & B & A & B & A & B & A & B \\
\hline \multicolumn{11}{|l|}{$H D N:$} \\
\hline No & 0 & 0 & 7 & 10 & 3 & 5 & 2 & 1 & 1 & 1 \\
\hline$\%$ & 00 & 00 & 53.8 & 58.8 & 23.1 & 29.4 & 15.4 & 5.9 & 7.7 & 5.9 \\
\hline \multicolumn{11}{|l|}{ HDR: } \\
\hline No & 0 & 0 & 8 & 11 & 3 & 4 & 1 & 1 & 1 & 1 \\
\hline$\%$ & 00 & 00 & 61.5 & 64.7 & 23.1 & 23.5 & 7.7 & 5.9 & 7.7 & 5.9 \\
\hline \multicolumn{11}{|l|}{$H S C:$} \\
\hline No & 0 & 0 & 7 & 12 & 4 & 5 & 1 & 0 & 1 & 0 \\
\hline$\%$ & 00 & 00 & 53.8 & 70.6 & 30.8 & 29.4 & 7.7 & 00 & 7.7 & 00 \\
\hline \multicolumn{11}{|l|}{ GST: } \\
\hline No & 0 & 0 & 7 & 12 & 4 & 5 & 1 & 0 & 1 & 0 \\
\hline$\%$ & 00 & 00 & 53.8 & 70.6 & 30.8 & 29.4 & 7.7 & 00 & 7.7 & 00 \\
\hline \multicolumn{11}{|l|}{$A F O:$} \\
\hline No & 0 & 0 & 9 & 13 & 4 & 4 & 0 & 0 & 0 & 0 \\
\hline$\%$ & 00 & 00 & 69.2 & 76.5 & 30.8 & 23.5 & 00 & 00 & 00 & 00 \\
\hline
\end{tabular}

HDN = Hair Density. $\quad$ GST $=$ General Satisfaction

$\mathrm{HDR}=$ Hair Direction. $\quad \mathrm{AFO}=$ Advice For Others to Do.

HSC $=$ Hidden Scars.

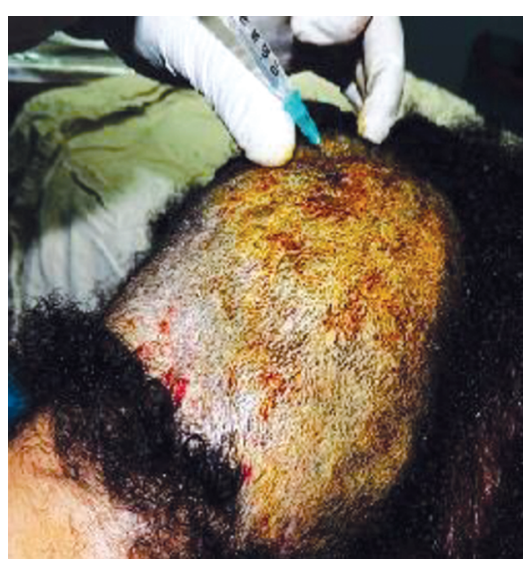

Fig. (1): Patient positioning and injection of local anesthesia.

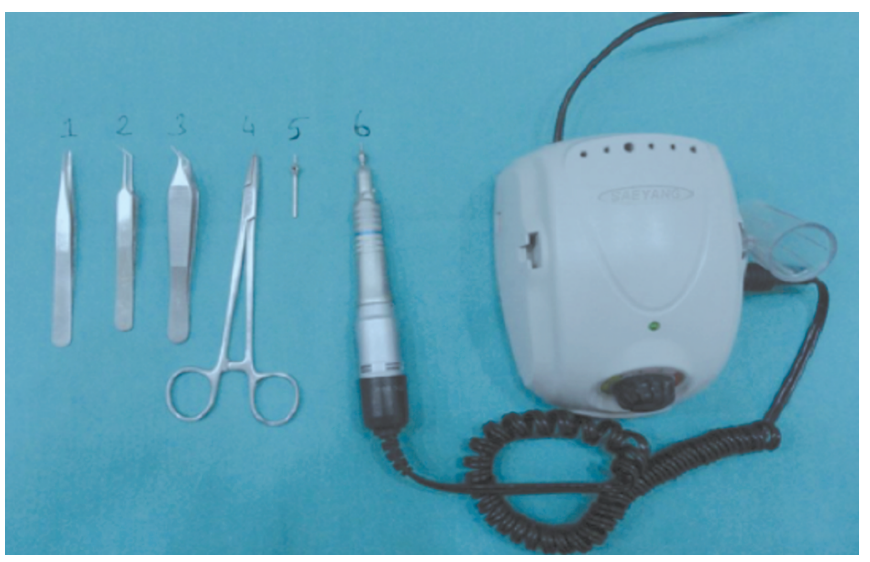

Fig. (2A): Instrument set used in hair transplantation.

Fig. (2B): Punch used for extraction ( $0.9 \mathrm{~mm}$ diameter $)$. 


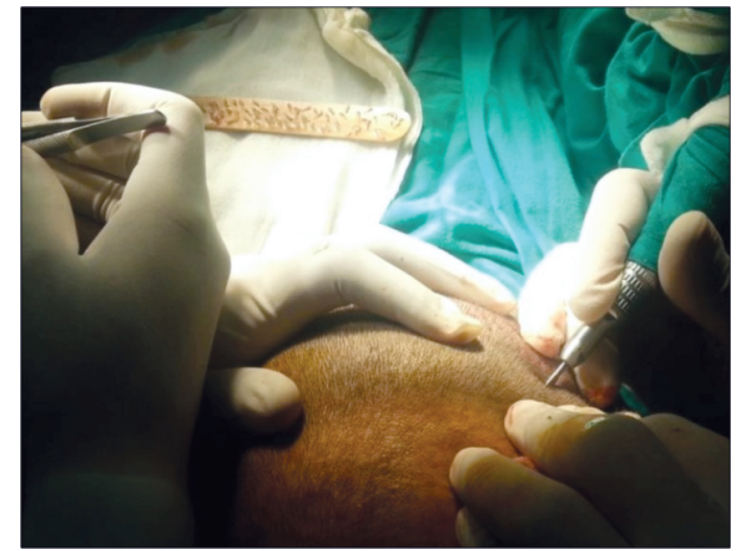

Fig. (3A): Graft harvesting.

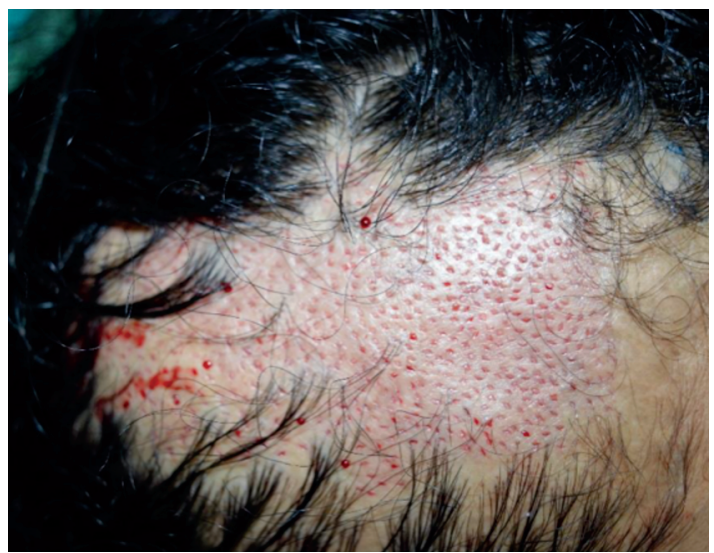

Fig. (3C): Recipient area with the receiving holes.

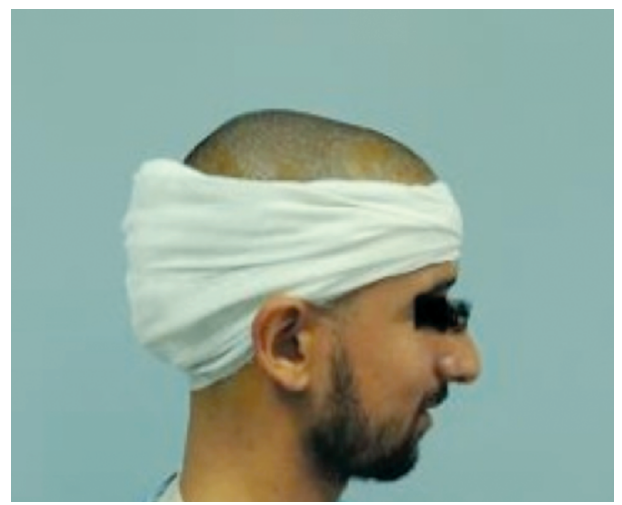

Fig. (3E): Post-procedure dressing; donor site is covered while the recipient area is left exposed.

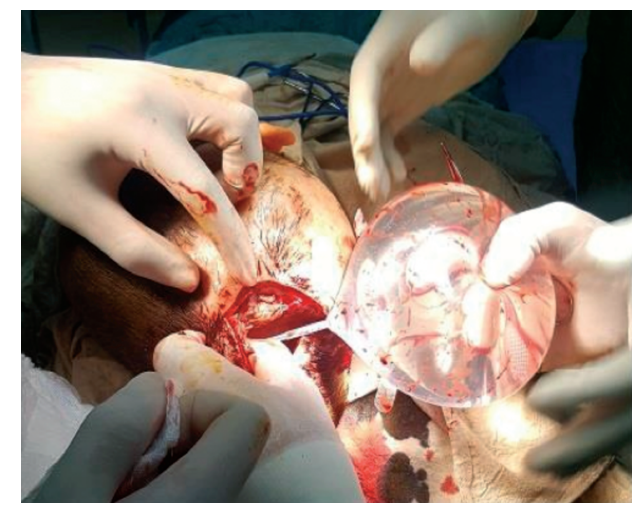

Fig. (4B): Expander Removal.

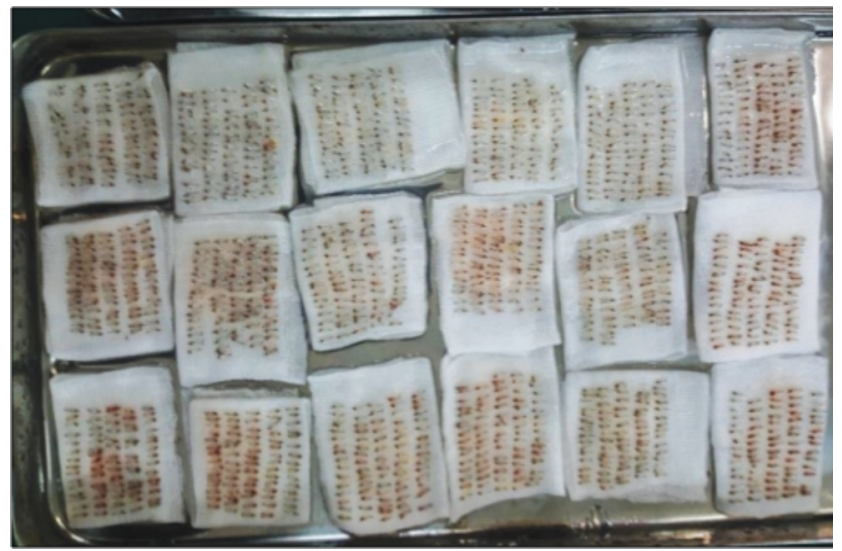

Fig. (3B): Grafts set on wet gauze.

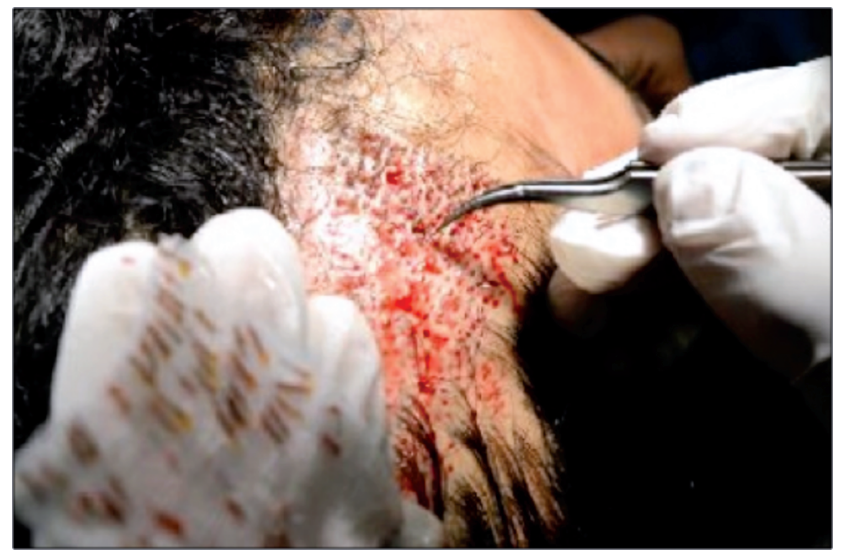

Fig. (3D): Insertion of FU grafts.

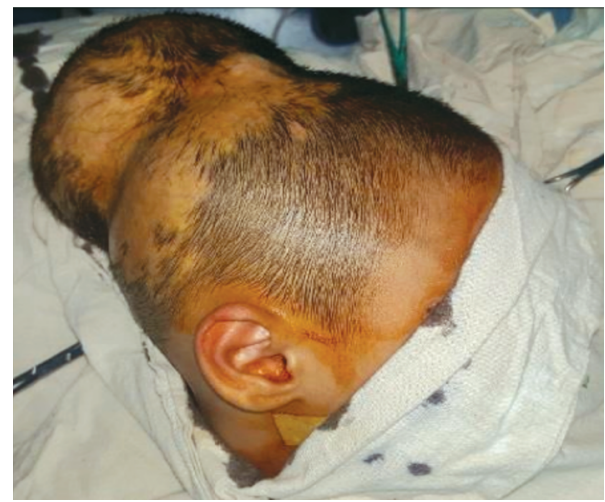

Fig. (4A): Scalp is expanded and ready for Stage II.

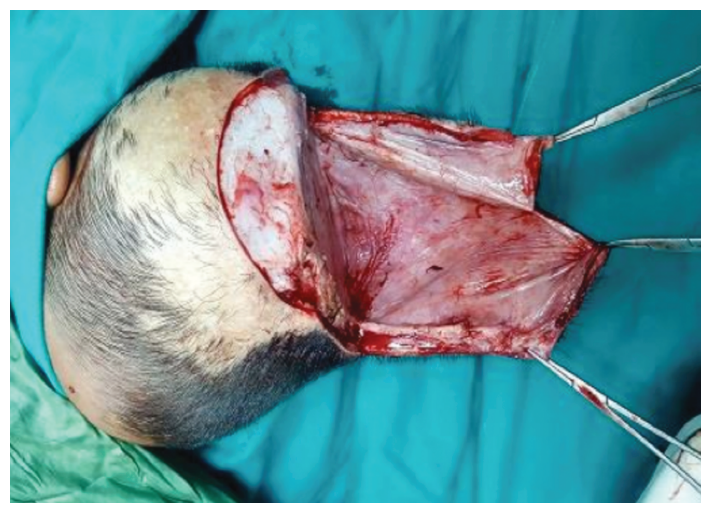

Fig. (4C): Expanded Flaps ready for advancement. 


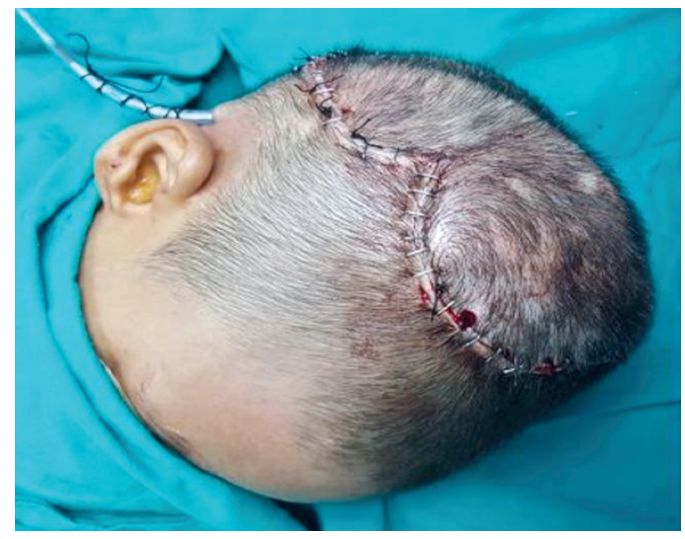

Fig. (4D): Wound closure with suction drain inserted.

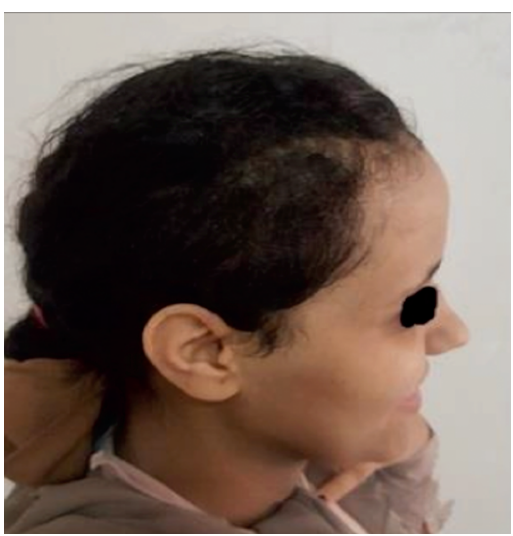

Fig. (5B): Same patient 6 months post-transplant.

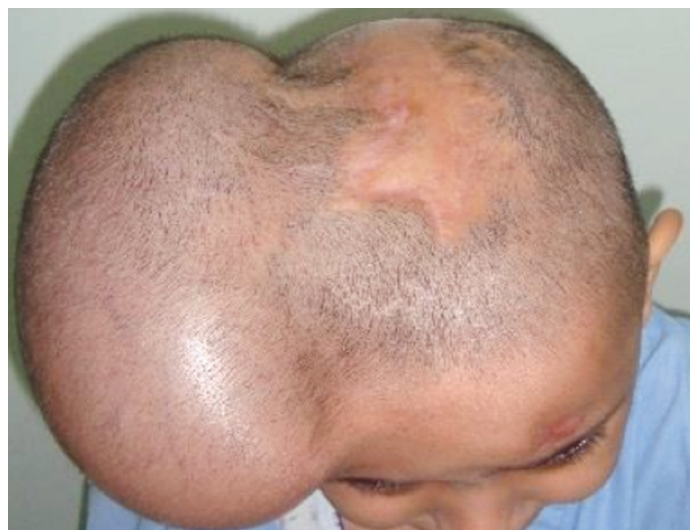

Fig. (6B): The same patient after full expansion.

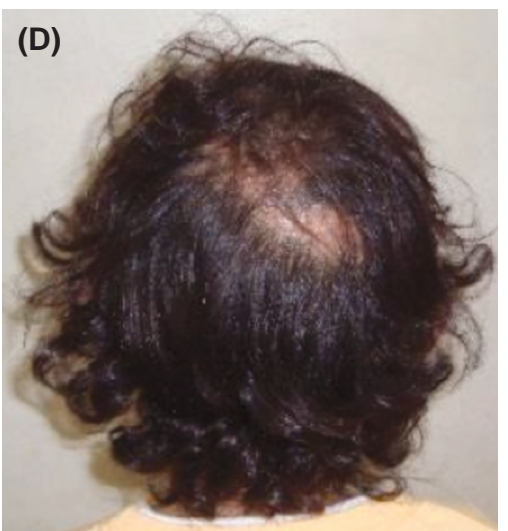

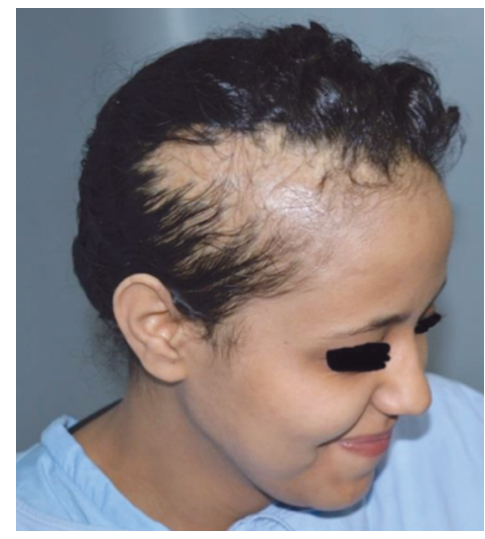

Fig. (5A): Rt. Temporal Post-burn alopecia (Before FUE).

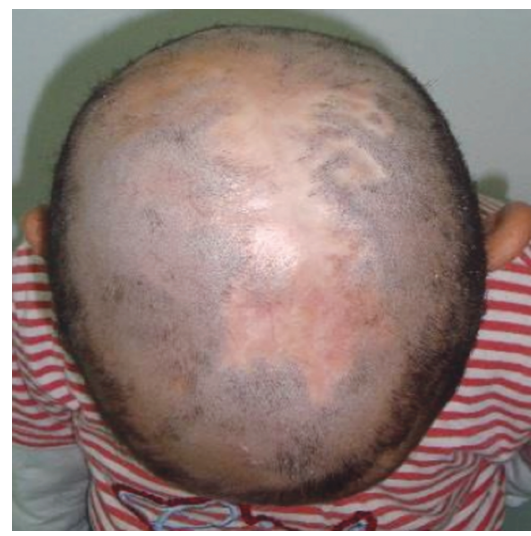

Fig. (6A): Mid-vault and upper occipital Post-burn alopecia in a 6 years old girl.

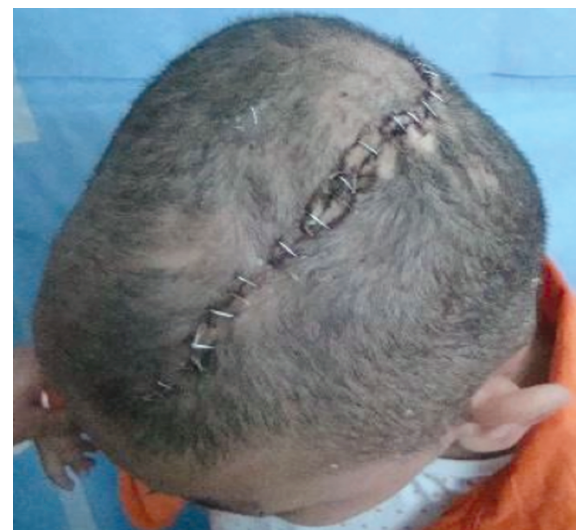

Fig. (6C): After removal of the expander.

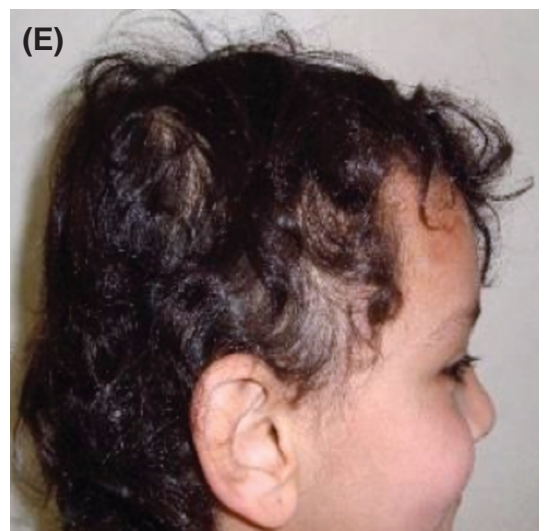

Fig. (6D,E): After one year. 


\section{DISCUSSION}

Secondary cicatricial alopecia is amenable to hair transplantation. Follicular unit grafts transplanted over scars can provide camouflage resulting in an improved cosmetic appearance, especially in highly visible areas, such as the scalp. Important considerations include wider spacing of grafts compared with regular hair transplantation of androgenic pattern hair loss because of the decreased vascularity over these scarred areas. Staged procedures can be done to increase density and improve coverage [8].

Meanwhile, expanders have been proved to be fruitful in the pediatric population. In particular, scalp expansion has proved to be useful in the reconstruction of posttraumatic and post-burn alopecic defects $[\mathbf{9 , 1 0 ]}$.

In this study, patient population was very heterogenous. While in Group A, most of patients were males (9/13) above the age of 15 years, Group $\mathrm{B}$ included 17 cases nearly equally distributed between males and females (males, 9/17) and their age range was extending between 6 to 26 years. Mean age \pm SD of both groups was $21.1 \pm 3.5$ in Group A and 13 \pm 2.8 in Group B, (Table 1).

Regarding Group A, this was slightly lower than that of Shau et al., 2014 [10] who made their work on 37 cases with their mean age \pm SD was of $24.7 \pm 5.9$ years. But, it is worthy to mention that in addition to the bigger number of cases who underwent FUE in this study, it was done over a period of 5 years. Meanwhile, for Group B, Tayyaba et al., 2015 [11] managed 30 cases of secondary cicatricial alopecia using scalp expansion within one year during the civil war in Pakistan (between 2013-2014). Their mean age \pm SD was $16 \pm 8.3$ years which is also quite near to our figures.

The mean values of the surface area of alopecia, in Group B was significantly larger than that of Group A $(p<0.001)$ (Table 3). In Group A, the mean surface area of alopecia $\mathrm{cm} 2$ was $22.91 \pm 15.1$, which differs from that given by Shau et al., 2014 [10] which was $10.08 \pm 19.55$ this may be because they limited their work to small linear scalp scars. In Group B, the mean surface area was $133.62 \pm$ 66.15, while Handschel et al., 2014 [12] studied 40 patients with mean surface area $40 \pm 43$ this is due to totally different patients as they studied only patients after radiotherapy (smaller scalp alopecic areas).

However, the time since exposure to the causative injury was significantly longer in Group A than that of Group B $(p<0.01)$ due to smaller defects in Group A that can be tolerated while in Group $\mathrm{B}$, larger surface area of defects with younger ages that cause psychological problems.

In the current study, the mean duration of hair transplantation in Group A was 3.12 \pm 1.42 hours which was very near to that recorded by Shau et al., 2014 [10] (3.61 \pm 1.32$)$. Also, there was no significant difference between both groups regarding the mean of operation duration $(p>0.05)$ (Table $3)$.

In this study, the mean follicular unit density per recipient area in Group A was 22.03 \pm 3.26 FU/ $/ \mathrm{cm}^{2}$ while Shau et al., 2014 [10] had the mean density of $36.28 \pm 6.44 \mathrm{FU} / \mathrm{cm}^{2}$. This difference was due to our consideration of the poor vascularity of the recipient area, so we were intended not to overcrowd the recipient area during implantation.

While in Group B, the mean expansion volume was $725 \pm 208$ Table (4), Handschel et al., 2014 [12] had mean expansion volume $224 \pm 189.03$ this might be due to relatively smaller alopecic areas he included in his study (Post-radiation therapy alopecia).

The total incidence of complications in Group A was $53.8 \%$, Table (5). But these complications occurred in 4 patients only and were recorded in the early cases at the onset of the study. This means that the real incidence of complications in Group $\mathrm{A}$ is $30.77 \%$. This is much bigger figure than that mentioned by Shau et al., 2014 [10] that were only $5.6 \%$. But we have to mention that he only recorded the long term complications including 2 patients out of 37 patients with epidermoid cysts.

In Group B we faced complications in $29.4 \%$ of patients. When comparing this figure with other studies, we found a great variation. Tayyabba et al., 2015 [11] faced complications incidence of $46.67 \%$, with $26 \%$ of them were due to mild infections. Chen et al., 2017 [13] stated that complications of the use of tissue expanders are controversial, having complications incidence of $6.25 \%$. They compared their results to that of Qing et al., 2006 [14] who faced $14 \%$ incidence of complications in a study of 57 patients and also to Saleh et al., 2004 [15] who faced complication rate of $21.5 \%$ in their study which is quite near to our figure. Also, Oh et al., 2010 [16] faced complications in $12.8 \%$ in their series of 62 patients and they referred this low incidence of complications to strict measures in postoperative care.

Although we couldn't attain excellent results in both groups (Table 6), we reached very good 
and good general patient satisfaction in Group A in 11 cases $(84.6 \%)$. Oh et al., 2010 [16] showed excellent results in $69.4 \%$, good results in $29 \%$, and bad result in only one patient (1.6\%). While Shau et al., 2014 [10] stated that patient Satisfaction at their study was $100 \%$ for 30 patients, $90 \%$ to $100 \%$ for five patients and $<90 \%$ for two patients.

Also in Group B, general patient satisfaction very good and good marks were recorded in all patients and neither any of the patient or their parents were unsatisfied. Drissi et al., 2007 [17] reported that their results were excellent and good in $90 \%$ of their expanded patients.

In another paper by Chen et al., 2017 [13], they adopted the use of scalp expansion combined with FUE for post-burn scalp alopecia. They reported excellent results in $60.5 \%$ and good results in $36.8 \%$ with only one patient $(2.7 \%)$ who was lost to follow-up. Although some of these figures are near to ours but still it is worthy to say that we have some limiting factors in our study.

First, is the short term of follow-up that was only one year. Second was the lack of definitive unified criteria that can objectively judge the final outcome. And this may be the reason why some of our figures in the final evaluation are different from others.

\section{Conclusion:}

In this study, we were able to certify that both hair transplantation and skin expansion are very useful in the field of cicatricial alopecia management. Also we reached to a conclusion that hair transplantation is a good option in alopecic areas less than $50 \mathrm{~cm}^{2}$ and patients above the age of 15 years (being able to understand and obey the PO instructions) while skin expansion is the best solution for bigger areas of alopecia and younger patients from the age of 5-6 years who can tolerate the process of expansion nicely.

\section{REFERENCES}

1- Ross E.K., Tan E. and Shapiro J.: Update on primary cicatricial alopecias. Journal of the American Academy of Dermatology, 53 (1): 1-37, 2005.

2- Tan E., Martinka M., Ball N. and Shapiro J.: Primary cicatricial alopecias: Clinicopathology of 112 cases. Journal of the American Academy of Dermatology, 50 (1): 25-32, 2004

3- Sowjanya C.L., Rao T.N., Guruprasad P. and Khopkar U.: Clinico-pathological study of acquired primary cicatricial alopecia. Journal of Dr. NTR University of Health Sciences, 1 (1): 21, 2012.

4- Dahdah M.J. and Iorizzo M.: The role of hair restoration surgery in primary cicatricial alopecia. Skin Appendage Disorders, 2 (1-2): 57-60, 2016.

5- Leedy J.E., Janis J.E. and Rohrich R.J.: Reconstruction of acquired scalp defects: An algorithmic approach. Plastic and Reconstructive Surgery, 116 (4): 54-72, 2005.

6- Dua A. and Dua K.: Follicular unit extraction hair transplant. Journal of Cutaneous and Aesthetic Surgery, 3 (2): 76, 2010.

7- El-Saadi M.M. and Nasr M.A.: The effect of tissue expansion on skull bones in the pediatric age group from 2 to 7 years. Journal of Plastic, Reconstructive \& Aesthetic Surgery, 61 (4): 413-418, 2008.

8- Barr L. and Barrera A.: Use of hair grafting in scar camouflage. Facial Plast. Surg. Clin North Am., 19: 55968, 2011.

9- Abo-Zeid M.A., Elmaddawy A.E.A., El-Fahar M.H. and El-Sabbagh A.H.: Selective scalp nerve block: A useful technique with tissue expansion in postburn pediatric alopecia. Ann. Plast. Surg., 80 (2): 113-120, 2018.

10- Shau H., Hang H., Yunyun J., Hongfei J., Chunmao H., Zhang J. and Guo X.: Follicular unit transplantation for the treatment of secondary cicatricial alopecia. Plastic Surgery, 22 (4): 249-253, 2014.

11- Tayyaba F., Amin M.M., Attaur-Rasool S., Naseer U. and Ambar A.: Reconstruction of post burn scalp alopecia by using expanded hair-bearing scalp flaps. Pakistan Journal of Medical Sciences, 31 (6): 1405, 2015.

12- Handschel J., Schultz S., Depprich R.A., Smeets R., Sproll C., Ommerborn M.A. and Zimmermann A.: Tissue expanders for soft tissue reconstruction in the head and neck area requirements and limitations. Clinical Oral Investigations, 17 (2): 573-578, 2013.

13- Chen H., Cheng H., Shen H., Li J., Jia M., Wang Y. and Zhang J.: Scalp soft tissue expansion combined with follicular unit extraction for postburn cicatricial alopecia: A single center experience of 48 patients. Int. J. Clin. Exp. Med., 10 (1): 774-780, 2017.

14- Qing Y., Cen Y. and Liu Y.: Prevention and treatment of postoperative complications after skin soft tissue expansion for scar alopecia. Chinese Journal of Reparative and Reconstructive Surgery, 20 (12): 1193-1195, 2006.

15- Saleh Y., Hafezi F., Naghibzadeh B. and Pegahmer M.: Scalp reconstruction using tissue expander. Egypt J. Plast. Reconstr., 28 (1): 71-75, 2004.

16- Oh S.J., Koh S.H., Lee J.W. and Jang Y.C.: Expanded flap and hair follicle transplantation for reconstruction of postburn scalp alopecia. J. of Craniofacial Surg., 21 (6): 1737 1740, 2010.

17- Drissi H.Q., Nassih M., Rzin A. and Jidal B.: Skin Expansion in cicatricial alopecia of the scalp: 18 cases. Revue de stomatologieet de chirurgie maxilla-faciale, 108 (5): 411-418, 2007. 